\title{
Haemodynamic Changes and Recovery Response after Intravenous Dexmedetomidine during Tracheal Extubation after General Anaesthesia
}

\author{
Somsubhra Pal ${ }^{1}$, Tirtha Ratan Ghosh ${ }^{2}$, Subrata Pahari ${ }^{3}$ \\ ${ }^{1}$ Senior Resident, Department of Anaesthesiology, Trauma Care Centre, IPGMER \& SSKM, Kolkata, West Bengal, India. \\ ${ }^{2}$ Assistant Professor, Department of Anaesthesiology, Bankura Sammilani Medical College, Bankura, West Bengal, \\ India. ${ }^{3}$ Professor and HOD, Department of Anaesthesiology, Bankura Sammilani Medical College, Bankura, West \\ Bengal, India.
}

\section{ABSTRACT}

\section{BACKGROUND}

Dexmedetomidine provides excellent sedation with minimal cardiovascular instability or respiratory depression and this has been widely used to attenuate intubation surge. This drug may be a useful adjunct to facilitate smooth tracheal extubation. The aim of this study was to evaluate the ability of dexmedetomidine to attenuate the haemodynamic responses during extubation.

\section{METHODS}

50 patients of ASA Grade I-II aged 20-50 years, were randomly allocated into two groups to receive either dexmedetomidine $0.75 \mu \mathrm{g} / \mathrm{Kg}$ in $100 \mathrm{ml}$ normal saline (Group D) or $100 \mathrm{ml}$ of normal saline (Group C) infusion over 15 minutes, initiated 15 mins., before anticipated end of surgery. Heart rate, systolic, diastolic and mean arterial pressures were assessed before, during and after extubation. Extubation quality was rated using 5-point scale. Sedation was rated using Ramsay Sedation Scale. Any adverse event was noted. Results were tabulated and statistically analysed using SPSS Software.

\section{RESULTS}

There was initially insignificant difference in mean $( \pm$ SD) HR, SBP, DBP in both the groups. HR became significantly higher at and after 5 minutes of start of infusion till observation continued in Group C. SBP, DBP, MAP were significantly lower ( $p<$ 0.05 ) in group D than $10 \mathrm{~min}$ after starting of infusion and there-after in all observation made up to 15 minutes postoperatively. Extubation quality score of the majority of patients was superior in group D than in group C. Sedation score of most patients was 3 in group D and 2 in group C. The incidence of adverse effects was statistically insignificant between the two groups ( $p$ valve $>0.05$ ).

\section{CONCLUSIONS}

Dexmedetomidine $(0.75 \mathrm{mcg} / \mathrm{Kg})$ infusion stabilizes haemodynamics and facilitates smooth extubation without causing undue sedation.

\section{KEY WORDS}

Dexmedetomidine, Extubation Quality, Haemodynamic Response

\author{
Corresponding Author: \\ Dr. Tirtha Ratan Ghosh \\ Flat No. B2/12, Shilpakanan Phase 3, \\ Bidhannagar, Durgapur-713206, \\ West Bengal, India. \\ E-mail: dr.tirthaghosh@gmail.com
}

DOI: $10.14260 /$ jemds/2019/687

Financial or Other Competing Interests: None.

How to Cite This Article:

Pal S, Ghosh TR, Pahari S. Haemodynamic changes and recovery response after intravenous dexmedetomidine during tracheal extubation after general anaesthesia. J. Evolution Med. Dent. Sci. 2019;8(42):3171-3176, DOI:
Submission 26-08-2019,

Peer Review 05-10-2019,

Acceptance 11-10-2019,

Published 21-10-2019. 


\section{BACKGROUND}

Management of airway is major concern in the practice of general anaesthesia (GA). ${ }^{1}$ Endotracheal extubation is the removal of a tube from the trachea via the nose or mouth. In GA it is done when the surgery is complete, after reversing the residual neuromuscular blockade and regaining of consciousness, when indication of artificial airway exist no more. ${ }^{2}$ Timing and technique of extubation are determined by the persisting residual effect of anaesthetic drugs and recovery of airway and other reflexes. ${ }^{3}$ During tracheal extubation, stimulus which affects haemodynamic changes are multifactorial like, light plane of anaesthesia, pain at surgical site, emergence from anaesthesia or tracheobronchial irritation and reflex sympathetic discharge caused by tracheopharyngeal \& laryngopharyngeal stimulation leading to tachycardia, hypertension, with or without arrhythmias. ${ }^{4,5}$ This transitory increase in heart rate and pressure are of little consequence in normal persons but are a matter of concern in patients with cardiovascular diseases like hypertension and coronary artery diseases, because this may lead to complications like angina, myocardial infarction and left ventricular failure due to dangerous increase in myocardial oxygen demand. 6 Aspiration, upper airway obstruction, bronchospasm and laryngospasm are respiratory complications encounter during extubation following GA.7

Various options are in vogue to attenuate extubation stress response which includes deeper planes of anaesthesia, topical anaesthesia, use of intravenous local anaesthetics, calcium channel blockers, opioids, and sympathetic blockers etc, $5,8,9$ but none have been completely successful. Alpha2agonists by its sympatholytic action potentiate the effects of general anaesthetics and attenuate stress responses to noxious stimuli encountered during anaesthesia and surgery, thus providing improved haemodynamic, metabolic, and hormonal stability. ${ }^{10}$ Dexmedetomidine, a highly selective alpha 2-adrenergic agonist, has sedative, anxiolytic and analgesic actions. It has been used for the treatment of the stress response to laryngoscopy successfully. ${ }^{11,12} \mathrm{We}$ hypothesized that use of dexmedetomidine before extubation might reduce stress-response of extubation, allow smooth extubation and improve overall recovery response during extubation. We conducted this prospective, randomized, double blind trial to check the efficacy of dexmedetomidine as an agent for attenuating the haemodynamic response of extubation.

The primary aim of this study was to evaluate the effect of intravenous Dexmedetomidine in reducing adverse haemodynamic response of extubation in patients undergoing general anaesthesia. The secondary aims were to observe the efficacy of Dexmedetomidine for smooth extubation and occurrence of any adverse effects including postoperative sedation.

\section{METHODS}

We carried out this study in our Institute after getting Ethical Committee permission. It was a prospective, randomized, double blind, clinical trial. Fifty consenting patients were selected for this study after careful consideration of inclusion and exclusion criteria. Inclusion criteria were of ASA American Society of Anesthesiologist physical status grades I and II, 20 to 50 years of age, of either sex and posted for elective surgeries for different indication under GA. Exclusion criteria were patients with neurological, endocrine, renal, hepatic and cardiovascular disease or abnormality and patients on psychotropic drugs or having history of drug allergies, anticipated or history of difficult airway. Informed consent was taken from each patient after through discussion regarding the nature of the study and the procedure during preanaesthetic check-up.

According to sample size calculation, 22 patients in each group were required to get a $90 \%$ power and $5 \%$ type I error where $15 \%$ difference between treatment group and control group was considered clinically significant. Sample size was increased by $10 \%$ to compensate any dropout during the study. So, the sample size was increased to 50 (25 patients in each group). Patients were randomly divided into Group D (Study group) and Group C (Control group) with 25 cases in each group with the help of computer-generated random number table.

After taking the patient in the operating room probes of multi-channel monitor were applied. ECG, heart rate (HR) and $\mathrm{SPO}_{2}$ were monitored continuously and non-invasive blood pressure (NIBP) were monitored at 5 minutes interval [systolic, diastolic and mean arterial pressure]. An IV line was started with Ringer's Lactate after putting an 18G cannula. The patients were premedicated with injection glycopyrrolate $4 \mathrm{mcg} / \mathrm{Kg}$; injection midazolam $0.025 \mathrm{mg} / \mathrm{Kg}$ and injection fentanyl $2 \mathrm{mcg} / \mathrm{Kg}$ intravenously. After preoxygenation for 3 minutes with standard protocol inj. Propofol administered slowly. Injection succinylcholine was used for intubation $(1.5 \mathrm{mg} / \mathrm{Kg}$ I.V.). Patients were intubated with disposable, high volume low pressure cuffed endotracheal tube of appropriate size following rigid laryngoscopy. Tube position was confirmed by clinical 5point auscultation and ventilation started with gas mixture of $33 \%$ oxygen in nitrous oxide. Initial tidal volume and rate of respiration were $8-10 \mathrm{ml} / \mathrm{Kg}$ and $12-15$ breaths per minute respectively and adjusted in such a way to maintain End Tidal $\mathrm{CO}_{2}\left(\mathrm{EtCO}_{2}\right)$ in between 35 to $40 \mathrm{~mm}$ of $\mathrm{Hg}$. For maintenance of muscle relaxation inj. Atracurium was used with loading dose $0.5 \mathrm{mg} / \mathrm{Kg}$ and followed by intermittent bolus dose of $0.1 \mathrm{mg} / \mathrm{Kg}$ as required. Inhalational agent Isoflurane $(0.5 \%$ $1 \%$ ) was used to maintain depth of anaesthetic plane during maintenance phase of GA. Inhalational agent was discontinued and infusion of drug solution was started 15 minutes before the expected completion of surgery. Dexmedetomidine $0.75 \mathrm{mcg} / \mathrm{Kg}$ body weight in $100 \mathrm{ml}$ of normal saline (NS) was used in Group D, while in Group C it was $100 \mathrm{ml} \mathrm{NS}$, infusion was completed over 15 minutes. To make the study double blinded both patient and observer were blinded to the group allocation. Allocation to two groups was confidential and concealed. One designated OR personnel who knew the patient's group allocation, prepared study drug solution (Dexmedetomidine $0.75 \mathrm{mcg} / \mathrm{Kg}$ body weight in $100 \mathrm{ml} \mathrm{NS}$ ) and control drug solution (100 ml NS) and dispensed in identical container $(100 \mathrm{ml} \mathrm{NS}$ Bottle) and both drug solutions were handed over to the observing anaesthesiologist. Drug composition in the dispensed bottle was unknown to observing anaesthesiologist. 
Heart rate and blood pressure, Systolic blood pressure (SBP), diastolic blood pressure (DBP) and mean arterial pressure (MAP) were recorded at the start of drug infusion and also at 1, 3, 5, 10 and 15 minutes after that. At the end of surgery, Inj. Neostigmine $0.05 \mathrm{mg} / \mathrm{Kg}$ and inj. Glycopyrrolate $0.01 \mathrm{mg} / \mathrm{Kg}$ were given intravenously to reverse the residual neuromuscular blockade after confirming the spontaneous partial recovery from muscle relaxant. At the time of reversal SBP, DBP and MAP were recorded. Extubation was done after getting spontaneous and smooth respiration, satisfactory response and thorough oropharyngeal suction. Haemodynamic parameters (HR, SBP, DBP and MAP) were recorded at the time of extubation and thereafter at $1,5,10$ and 15 minutes after extubation. A 5-point rating scale, Extubation Quality Score (EQS) ${ }^{13}$ was used to assess the quality of extubation process based on the parameter of coughing immediately after extubation.

\section{EQS}

1. No coughing.

2. Smooth extubation, minimal coughing.

3. Moderate coughing ( 3 or 4 times).

4. Severe coughing (5-10 times) and straining.

5. Poor extubation, very uncomfortable (Laryngospasm and coughing $>10$ times).

Extubation Quality Score 1 and 2 were considered as smooth extubation and desired state of extubation. Whereas EQS 3 or more were considered as uncomfortable extubation. Postoperative sedation was assessed by Ramsay Sedation Scale (RSS). ${ }^{14}$ Here sedation was evaluated by the 6-point scale.

\section{RSS}

\section{If Awake}

1- Anxious, agitated, restless.

2- Cooperative, oriented, tranquil.

3- Responsive to commands only.

\section{If Asleep}

4- Brisk response to light glabellar tap or loud auditory stimulus.

5- Sluggish response to light glabellar tap or loud auditory stimulus.

6- No response to light glabellar tap or loud auditory stimulus.

Patients with RSS score 2 was considered as Awake and tranquil patients and that is desirable postoperative outcome. Other score of RSS were considered as Anxious or drowsy patients which are not desirable postoperatively. Patients were observed for bradycardia, hypotension, nauseavomiting, laryngospasm, bronchospasm, respiratory depression and desaturation or any other drug related adverse effects. Any anaesthesia related problems were observed, recorded and was attended appropriately.

\section{Statistical Analysis}

The results were tabulated and statistically analysed using IBM SPSS Software. Unpaired t-test was used for continuous variables with normal distribution and chi-square test for categorical variables. The results were written as mean \pm standard deviation, number of patients, percentage of total patient. $\mathrm{p}$ value $<0.05$ was considered as statistically significant.

\section{RESULTS}

Age, sex, weight and ASA physical status (Demographic parameters) in two groups were comparable.[Table 1] Heart rate in two groups were comparable at base line, 1 minute and 3 minutes. Difference in HR of two groups were observed from 5 minutes after starting administration of the infusion and continued till 15 minutes after extubation which were statistically significant. Heart rate in Group D was lower than control group [Table 2]. Initial comparable SBP into two groups from baseline to 5 minutes after initiation of drug infusion changed to higher systolic blood pressure in Group C at 10 minutes after drug infusion and the values remain higher in group $\mathrm{C}$ throughout the remaining study period which are statistically significant [Table 3]. Similarly initial comparable DBP and MAP into two groups from baseline to 5 minutes after initiation of drug infusion changed to higher systolic blood pressure in Group C at 10 minutes after drug infusion and the values remain higher in group $\mathrm{C}$ throughout the remaining study period which are statistically significant [Table 4,5$]$. Smooth extubation was possible in $96 \%$ of the patients in group D whereas $28 \%$ in group C. This difference is statistically highly significant. Only $1(14 \%)$ patient from Group D suffered uncomfortable extubation but in Group C it was $18(72 \%)$ [Table 6]. While analysing postoperative sedation status we found $15(60 \%)$ patients from Group C and $9(36 \%)$ patients from Group D had RSS score 2 which is a desired or preferred score in immediate postoperative period. Ten (40\%) patients from Group C and 16 (64\%) patients from Group D were either anxious or drowsy. These differences are not statistically significant $(p=0.093)$ [Table 6]. Three patients from Group C and 4 patients from Group D suffered bradycardia but none of them required treatment and the difference is not statically significant [Table 6]. No one from Group C suffered from hypotension where only 1 patient from Group D had hypotension though that patient did not require any vasopressor therapy for hypotension.

\begin{tabular}{|c|c|c|c|}
\hline Parameters & Group C (n = 25) & Group D (n = 25) & p \\
\hline Age (in years) & $35.88 \pm 9.74$ & $36.48 \pm 9.21$ & 0.824 \\
\hline Weight (in KG) & $58.36 \pm 6.92$ & $59.44 \pm 7.37$ & 0.596 \\
\hline Gender (Male:Female) & $10: 15$ & $9: 16$ & 0.773 \\
\hline ASA - PS (Grade I: Grade II) & $18: 7$ & $16: 9$ & 0.548 \\
\hline
\end{tabular}

Table 1. Comparison of Demographic Data $\mathrm{n}$ - Patient in each group, $\mathrm{p}$ value less than 0.05 is statistically significant.

\begin{tabular}{|c|c|c|c|}
\hline $\begin{array}{c}\text { Time of } \\
\text { Recording }\end{array}$ & $\begin{array}{c}\text { HR of Group C } \\
\text { (Beats/ min)(n = 25) }\end{array}$ & $\begin{array}{c}\text { HR of Group D } \\
\text { (Beats / min) (n = 25) }\end{array}$ & p \\
\hline At baseline & $85.48 \pm 12.08$ & $83.20 \pm 10.95$ & 0.488 \\
\hline 1 minute of infusion & $83.72 \pm 10.89$ & $83.88 \pm 11.24$ & 0.959 \\
\hline 3 minutes of infusion & $81.72 \pm 10.83$ & $79.96 \pm 9.75$ & 0.549 \\
\hline 5 minutes of infusion & $82.40 \pm 9.82$ & $76.04 \pm 9.48$ & 0.024 \\
\hline 10 minutes of infusion & $79.28 \pm 8.60$ & $72.44 \pm 8.56$ & 0.008 \\
\hline 15 minutes of infusion & $83.72 \pm 10.73$ & $70.08 \pm 11.13$ & 0.000 \\
\hline Atreversal & $95.68 \pm 9.87$ & $80.12 \pm 11.22$ & $<0.000$ \\
\hline At extubation & $112.00 \pm 13.59$ & $86.88 \pm 13.27$ & $<0.000$ \\
\hline 1 minute after extubation & $107.04 \pm 13.87$ & $82.12 \pm 11.72$ & $<0.000$ \\
\hline 5 minutes after extubation & $98.92 \pm 12.42$ & $76.40 \pm 11.81$ & $<0.000$ \\
\hline 10 minutes after extubation & $91.44 \pm 10.62$ & $72.48 \pm 11.41$ & $<0.000$ \\
\hline 15 minutes after extubation & $89.32 \pm 9.77$ & $71.08 \pm 9.66$ & $<0.000$ \\
\hline \multicolumn{4}{|r|}{ Table 2. Comparison of Heart Rate } \\
\hline n - Patient in each group, p value less than 0.05 is statistically significant. \\
\hline
\end{tabular}




\begin{tabular}{|c|c|c|c|}
\hline $\begin{array}{c}\text { Time of } \\
\text { Recording }\end{array}$ & $\begin{array}{c}\text { SBP of Group C } \\
\text { (mmHg) (n = 25) }\end{array}$ & $\begin{array}{c}\text { SBP of Group D } \\
\text { (mmHg) (n = 25) }\end{array}$ & p \\
\hline At baseline & $129.92 \pm 9.97$ & $131.20 \pm 10.86$ & 0.667 \\
\hline 1 minute of infusion & $129.84 \pm 10.07$ & $130.48 \pm 11.93$ & 0.839 \\
\hline 3 minutes of infusion & $131.96 \pm 9.76$ & $132.72 \pm 12.11$ & 0.808 \\
\hline 5 minutes of infusion & $130.28 \pm 9.26$ & $131.08 \pm 11.46$ & 0.787 \\
\hline 10 minutes of infusion & $132.04 \pm 7.92$ & $125.84 \pm 9.18$ & 0.014 \\
\hline 15 minutes of infusion & $135.64 \pm 9.62$ & $122.80 \pm 10.97$ & 0.000 \\
\hline At reversal & $142.56 \pm 7.86$ & $131.28 \pm 12.82$ & 0.000 \\
\hline At extubation & $150.52 \pm 5.75$ & $138.40 \pm 12.83$ & $<0.000$ \\
\hline 1 minute after extubation & $144.72 \pm 5.58$ & $134.52 \pm 11.20$ & $<0.000$ \\
\hline 5 minutes after extubation & $139.08 \pm 6.10$ & $126.68 \pm 10.95$ & $<0.000$ \\
\hline 10 minutes after extubation & $136.28 \pm 7.52$ & $122.48 \pm 11.34$ & $<0.000$ \\
\hline 15 minutes after extubation & $133.84 \pm 7.86$ & $120.48 \pm 12.08$ & $<0.000$ \\
\hline \multicolumn{4}{|c|}{ Table 3. Comparison of Systolic Blood Pressure } \\
\hline n - Patient in each group, p value less than 0.05 is statistically significant. \\
\hline \multicolumn{4}{|l}{} \\
\hline
\end{tabular}

\begin{tabular}{|c|c|c|c|}
\hline $\begin{array}{c}\text { Time of } \\
\text { Recording }\end{array}$ & $\begin{array}{c}\text { DBP of Group C } \\
(\mathrm{mmHg})(\mathrm{n}=25)\end{array}$ & $\begin{array}{l}\text { DBP of Group D } \\
(\mathrm{mmHg})(\mathrm{n}=25)\end{array}$ & $\mathbf{p}$ \\
\hline At baseline & $81.64 \pm 7.94$ & $84.80 \pm 10.64$ & 0.240 \\
\hline 1 minute of infusion & $81.04 \pm 8.77$ & $83.96 \pm 9.14$ & 0.255 \\
\hline 3 minutes of infusion & $83.72 \pm 8.52$ & $87.32 \pm 9.65$ & 0.169 \\
\hline 5 minutes of infusion & $82.52 \pm 9.77$ & $86.96 \pm 8.24$ & 0.089 \\
\hline 10 minutes of infusion & $84.36 \pm 8.85$ & $79.24 \pm 7.04$ & 0.028 \\
\hline 15 minutes of infusion & $85.32 \pm 6.66$ & $77.40 \pm 7.18$ & 0.000 \\
\hline At reversal & $92.16 \pm 6.60$ & $83.12 \pm 8.35$ & 0.000 \\
\hline At extubation & $96.84 \pm 6.46$ & $85.44 \pm 7.62$ & $<0.000$ \\
\hline 1 minute after extubation & $92.92 \pm 5.76$ & $85.64 \pm 8.06$ & 0.000 \\
\hline 5 minutes after extubation & $89.12 \pm 5.54$ & $79.68 \pm 7.67$ & $<0.000$ \\
\hline 10 minutes after extubation & $87.12 \pm 6.95$ & $75.52 \pm 8.56$ & $<0.000$ \\
\hline 15 minutes after extubation & $83.88 \pm 7.45$ & $73.08 \pm 8.70$ & $<0.000$ \\
\hline \multicolumn{4}{|c|}{ Table 4. Comparison of Diastolic Blood Pressure } \\
\hline
\end{tabular}

\begin{tabular}{|c|c|c|c|}
\hline $\begin{array}{c}\text { Time of } \\
\text { Recording }\end{array}$ & $\begin{array}{c}\text { MAP of Group C } \\
\text { (mmHg) (n = 25) }\end{array}$ & $\begin{array}{c}\text { MAP of Group D } \\
\text { (mmHg) (n = 25) }\end{array}$ & p \\
\hline At baseline & $97.56 \pm 7.25$ & $100.24 \pm 9.43$ & 0.266 \\
\hline 1 minute of infusion & $97.32 \pm 8.13$ & $99.36 \pm 8.73$ & 0.397 \\
\hline 3 minutes of infusion & $99.64 \pm 7.32$ & $102.40 \pm 9.07$ & 0.242 \\
\hline 5 minutes of infusion & $98.44 \pm 8.65$ & $101.56 \pm 8.57$ & 0.206 \\
\hline 10 minutes of infusion & $100.28 \pm 7.45$ & $94.48 \pm 7.04$ & 0.007 \\
\hline 15 minutes of infusion & $102.08 \pm 6.45$ & $92.52 \pm 7.46$ & $<0.000$ \\
\hline At reversal & $109.04 \pm 5.26$ & $99.08 \pm 8.57$ & $<0.000$ \\
\hline At extubation & $114.72 \pm 5.41$ & $103.28 \pm 7.59$ & $<0.000$ \\
\hline 1 minute after extubation & $110.24 \pm 4.87$ & $101.80 \pm 7.52$ & $<0.000$ \\
\hline 5 minutes after extubation & $105.72 \pm 4.77$ & $95.28 \pm 7.40$ & $<0.000$ \\
\hline 10 minutes after extubation & $103.44 \pm 6.06$ & $91.16 \pm 8.15$ & $<0.000$ \\
\hline 15 minutes after extubation & $100.48 \pm 6.49$ & $88.88 \pm 8.71$ & $<0.000$ \\
\hline \multicolumn{4}{|c|}{ Table 5. Comparison of Mean Arterial Pressure } \\
\hline n - Patient in each group, p value less than 0.05 is statistically significant. \\
\hline
\end{tabular}

\begin{tabular}{|c|c|c|c|}
\hline Parameters & $\begin{array}{l}\text { Group C } \\
(n=25)\end{array}$ & $\begin{array}{c}\text { Group D } \\
(n=25)\end{array}$ & $\mathbf{p}$ \\
\hline \multicolumn{4}{|c|}{ Extubation Quality Score (Score 1 to score 5) } \\
\hline Smooth extubation (Score 1 \&2) & $7(28 \%)$ & $24(96 \%)$ & \multirow[b]{2}{*}{$\mathrm{p}<0.001$} \\
\hline Uncomfortable extubation (Score 3,4 \& 5) & $18(72 \%)$ & $01(4 \%)$ & \\
\hline \multicolumn{4}{|c|}{ Ramsey Sedation Score (Score 1 to Score 6) } \\
\hline Awake and tranquil patients (Score 2) & $15(60 \%)$ & $9(36 \%)$ & \multirow{2}{*}{$\mathrm{p}=0.093$} \\
\hline Anxious and drowsy patients (Score $1,3,4,5, \& 6$ ) & $10(40 \%)$ & $16(64 \%)$ & \\
\hline \multicolumn{4}{|l|}{ Adverse Effects } \\
\hline Bradycardia ( $\mathrm{HR}<60$ beats $/$ minute) & $3(12 \%)$ & $4(16 \%)$ & $\mathrm{p}=0.687$ \\
\hline Hypotension (MAP < $60 \mathrm{mmHg}$ ) & 0 & $1(4 \%)$ & $\mathrm{p}=0.317$ \\
\hline Nausea and vomiting & $3(12 \%)$ & $3(12 \%)$ & $\mathrm{p}=1.000$ \\
\hline Laryngospasm & 0 & 0 & \\
\hline Bronchospasm & 0 & 0 & \\
\hline Respiratory depression & 0 & 0 & \\
\hline Desaturation & 0 & 0 & \\
\hline \multicolumn{4}{|c|}{ Table 6. Comparison of Extubation Quality, Sedation and Adverse Effects } \\
\hline $\mathrm{n}$ - Patient in each group, $\mathrm{p}$ value less than $0.05 \mathrm{i}$ & cstatictica & significant. & \\
\hline
\end{tabular}

Incidence of nausea and vomiting was very same in both group (3 patients in each group). There was no laryngospasm, bronchospasm, respiratory depression and desaturation in any group [Table 6].

\section{DISCUSSION}

Emergence from general anaesthesia and tracheal extubation is often accompanied with tachycardia and hypertension. ${ }^{15}$
Tracheal intubation and extubation are accompanied by raised sympathoadrenal activity with an increased plasma catecholamine levels which cause an increase in HR, BP, myocardial contractility and increased systemic vascular resistance. ${ }^{16,17}$ These may cause myocardial ischemia or infarction in susceptible patients. ${ }^{18}$ Alpha-2 agonists decrease the sympathetic and noradrenergic activity, thereby counteract the rise of HR, SBP, DBP and MAP at the time of extubation due to increased sympathetic stimulation.18 Dexmedetomidine, an $\alpha 2$-adrenoreceptor agonist has been successfully used for attenuating the stress response to laryngoscopy.11,12

During review of literature we found that different dose of Dexmedetomidine has been used. Many authors have used it with the dose of $0.5 \mathrm{mg} / \mathrm{Kg}^{13,19,20}$ but Bindu et al. ${ }^{2}$ in their pilot study found that a dose of $0.5 \mathrm{mcg} / \mathrm{Kg}$ gave insignificant results and a dose of $1 \mathrm{mcg} / \mathrm{Kg}$ sometimes resulted in haemodynamic instability. In their final study they used Dexmedetomidine in a dose of $0.75 \mathrm{mcg} / \mathrm{Kg}$ body weight. So we also used $0.75 \mathrm{mcg} / \mathrm{Kg}$ in $100 \mathrm{ml}$ normal saline over 15 minutes, started 15 minutes before the expected end of surgery, and assessed for efficacy of it over the placebo in reducing haemodynamic stress response, smooth extubation, postoperative sedation and adverse effects during tracheal extubation.

In our study after infusion of study drug and placebo, HR and blood pressure (SBP, DBP, MAP) were lower in Dexmedetomidine group. By its highly selective $\alpha_{2}$ agonistic action Dexmedetomidine reduces concentration of epinephrine, causes sympatholytic action and attenuates stress response. ${ }^{13}$ Bindu et. al. also found that lower heart rate and BP in the group which received infusion of Dexmedetomidine. ${ }^{2}$ Turan et al. used Dexmedetomidine 5 min before the end of surgery in a dose of $0.5 \mathrm{mcg} / \mathrm{Kg}$ over 60 seconds and they also concluded that HR and BP were lower in Dexmedetomidine group just before extubation at extubation and upto 30 mins after extubation. ${ }^{13}$ Guler et al. used it for extubation in intraocular surgery and haemodynamic result was similar. In their study systolic and diastolic pressure both increased in both groups, but increase was less in Dexmedetomidine receiving group. One patient had bradycardia and three patients had hypotension that group. Dexmedetomidine $0.5 \mathrm{mcg} / \mathrm{Kg}$ in $100 \mathrm{ml}$ NS over 60 seconds was used for this study. ${ }^{19}$

In our study HR started to decrease 5 minutes after initiation of infusion whereas SBP, DBP and MAP started to decrease 10 minutes after initiation of infusion, which can be explained by the short onset of action of Dexmedetomidine (Less than 5 minutes) ${ }^{20}$ and lack of real time monitoring for SBP, DBP and MAP.

Dexmedetomidine due to its analgesic and sedative properties helps to blunt airway reflexes. In our study incidence of coughing and uncomfortable extubation with EQS scores 3 or more was significantly higher $(\mathrm{P}<0.001)$ in control group than study group ( $72 \%$ vs $4 \%$ respectively).

This is in accordance with study done by Aksu et al where prevalence of no-cough-patients was $85 \%$ in Dexmedetomidine group and $30 \%$ in fentanyl group ${ }^{21}$. Guler et al. also noted that the effect of dexmedetomidine on children undergoing adenotonsillectomy where dexmedetomidine group had significantly less incidence and 
severity of agitation and a smooth extubation. ${ }^{20}$ In another study Guler et al. also found that smoother extubation when Dexmedetomidine has been used, 9 patients developed cough on extubation comparison to 19 patients in placebo group. ${ }^{19}$ Eighty-four percent patient experienced cough in placebo group but it comes down to 16 percent in Dexmedetomidine group in the study of Bindu et al. ${ }^{2}$

Regarding postoperative sedation $60 \%$ and $36 \%$ patients were awake and tranquil in group $\mathrm{C}$ and group $\mathrm{D}$ respectively, though these differences are not statistically significant. Bindu et al. found RSS score 3 in most patients of the Dexmedetomidine group whereas it was 2 in most of the patients of placebo group. ${ }^{2}$ Dexmedetomidine has definitively sedative action but it does not affect adversely rather make the the patient comfortable in immediate postoperative period.

Our study did not find significant difference in the incidence of bradycardia, hypotension, nausea and vomiting between the two groups. There was no respiratory depression, laryngospasm, bronchospasm, undue sedation or desaturation in any patient of either group. Similar findings have been made by Guler et al. ${ }^{19}$ Some study has reported minor adverse effect. A very few patients developed bradycardia, hypotension and vomiting but none of these patients required any treatment for hypotension or bradycardia.2,13

\section{CONCLUSIONS}

Dexmedetomidine $0.75 \mathrm{mcg} / \mathrm{Kg}$ body wt. in $100 \mathrm{ml}$ normal saline over 15 minutes initiated 15 minutes before anticipated end of surgery was able to attenuate the haemodynamic response to tracheal extubation. It allows smooth extubation of the trachea and doesn't cause undue sedation postoperatively. There is incidence of bradycardia, hypotension, nausea and vomiting, though not requiring urgent intervention and was not statistically significant.

\section{REFERENCES}

[1] Pollard BJ, Norton ML. Principles of airway management. In: Thomas HEJ, Paul KR, eds. Wyle and Churchill Davidson's Practice of Anaesthesia. $7^{\text {th }}$ edn. London: Arnold Publication 2003: p. 443.

[2] Bindu B, Pasupuleti S, Gowd UP, et al. A double blind randomized, controlled trial to study the effect of dexmedetomidine on haemodynamic and recovery response during tracheal extubation. Journal of Anaesthesiology \& Clinical Pharmacology 2013;29(2):162-7.

[3] Peterson GN, Domino KB, Caplan RA, et al. Management of the difficult airway: a closed claims analysis. Anaesthesiology 2005;103(1):33-9.

[4] Fuji Y, Saitoh Y, Takahashi S, et al. Combined diltiazem and lidocaine reduces cardiovascular responses to tracheal extubation and anaesthesia emergence in hypertensive patients. Can J Anaesth 1999;46(10):952-6.

[5] Nishina K, Mikawa K, Maekawa N, et al. Attenuation cardiovascular responses to tracheal extubation with diltiazem. Anaesth Analg 1995;80(6):1217-22.

[6] Goarya RS, Mathur A. I/V bolus dexmeditomidine attenuates the airway reflexes and haemodynamic responses during extubation following general anaesthesia. Journal of Evolution of Medical and Dental Sciences 2014;3(65):14114-28.

[7] Tanaka A, Isono S, Ishikawa T, et al. Laryngeal reflex before and after placement of airway interventions. Endotracheal tube and laryngeal mask airway. Anaesthesiology 2005;102(1):20-5.

[8] Bidwai VA, Bidwai AV, Rogers CR, et al. Blood-pressure and pulse-rate responses to endotracheal extubation with and without prior injection of lidocaine. Anaesthesiology 1979;51(2):171-3.

[9] Muzzi DA, Black S, Losasso TJ, et al. Labetalol and esmolol in the control of hypertension after intracranial surgery. Anaesth Analg 1990;70(1):68-71.

[10] Maze M, Segal IS, Bloor BC. Clonidine and other alpha2 adrenergic agonists: strategies for the rational use of these novel anaesthetic agents. J Clin Anaesth 1988;1(2):146-57.

[11] Bhana N, Goa KL, McClellan KJ. Dexmedetomidine. Drugs 2000;59(2):263-8, discussion 269-70.

[12] Sulaiman S, Karthekeyan RB, Vakamudi M, et al. The effects of Dexmedetomidine on attenuation of stress response to endotracheal intubation in patients undergoing elective off pump coronary artery bypass grafting. Ann Card Anaesth 2012;15(1):39-43.

[13] Turan G, Ozgultekin A, Turan C, et al. Advantageous effects of dexmedetomidine on haemodynamic and recovery responses during extubation for intracranial surgery. Eur J Anaesthesiol 2008;25(10):816-20.

[14] Ramsay M, Savege TM, Simpson BR, et al. Controlled sedation with alphaxalone-alphadone. $\mathrm{Br}$ Med J 1974;2(5920):656-9.

[15] Hartley M, Vaughan RS. Problems with tracheal extubation. Br J Anaesth 1993;71(4):561-8.

[16] Paulissian R, Salem MR, Joseph NJ, et al. Hemodynamic responses to endotracheal extubation after coronary artery bypass grafting. Anaesth Analg 1991;73(1):10-5.

[17] Lowrie A, Johnson PL, Fell D, et al. Cardiovascular and plasma catecholamine responses at tracheal extubation. Br J Anaesth 1992;68(3):261-3.

[18] Jain D, Khan R, Maroof M. Effect of dexmedetomidine on stress response to extubation. The Internet Journal of Anaesthesiology 2009;21:14.

[19] Guler G, Akin A, Tosun Z, et al. Single-dose dexmedetomidine attenuates airway and circulatory reflexes during extubation. Acta Anaesthesiol Scand 2005;49(8):1088-91.

[20] Guler G, Akin A, Tosun Z, et al. A single - dose dexmedetomidine reduces agitation and provides smooth extubation after pediatric adenotonsillectomy. Paediatr Anaesth 2005;15(9):762-6. 
[21] Aksu R, Akin A, Bicer C, et al. Comparison of the effects of dexmedetomidine versus fentanyl on airway reflexes and haemodynamic responses to tracheal extubation during rhinoplasty: a double - blind, randomized, controlled study. Curr Ther Res Clin Exp 2009;70(3):209-20. 